\title{
Discrimination between FRC-post and core according to the color difference
}

\author{
Jou-Hwe Kim, Jin-Woo Kim, Kyung-Mo Cho, Se-Hee Park* \\ Department of Conservative Dentistry, College of Dentistry, Gangneung-Wonju National University, Gangneung, Republic of Korea
}

Purpose: The purpose of this study is to evaluate which FRC-posts were more distinguishable from core. Materials and Methods: Nine extracted single-rooted mandibular premolars with similar lengths $( \pm 0.5 \mathrm{~mm}$ ) and widths $( \pm 0.5 \mathrm{~mm})$ were endodontically treated and obturated. One specimen which the three roots were embedded in a cold mounting resin was made. 3 specimens were made by this method. Post spaces were prepared for the following post system: FRC Postec ${ }^{\circledR}$ Plus, MACRO-LOCK ${ }^{\mathrm{TM}}$ POST ILLUSION $^{\mathrm{TM}}$ $\mathrm{XRO}^{\circledast}$, Snowpost ${ }^{\circledR}$. After three different posts were placed in the roots of a specimen, each three specimens received a direct core build-up: Luxacore ${ }^{\circledR}$ Dual A3, Luxacore ${ }^{\circledR}$ Dual blue, Filtek ${ }^{\mathrm{TM}} \mathrm{Z} 350$ A1E. Digital images were taken of the post and core with and without air-blowing. We asked to fifty dentists and fifty dental college students which post was more clearly discriminated from the core. Results: In surveys, when core was Luxacore ${ }^{\circledR}$ Dual blue, among three types of posts people more easily discriminated the Snowpost ${ }^{\circledR}$ from core. When core was Luxacore ${ }^{\circledR}$ Dual $A 3$, among three types of posts people similarly more easily discriminated Snowpost ${ }^{\circledR}$ from core. When core was Filtek ${ }^{\mathrm{TM}} \mathrm{Z} 350 \mathrm{~A} 1 \mathrm{E}$, among three types of posts people more easily discriminated distinguished MACRO-LOCK ${ }^{\mathrm{TM}}$ POST ILLUSION ${ }^{\mathrm{TM}} \mathrm{XRO}^{\circledR}$ post from core. People more easily distinguished MACRO-LOCK ${ }^{\mathrm{TM}}$ POST ILLUSION $^{\mathrm{TM}}$ XRO $^{\circledR}$ post from core when temperature was lowered by air-blowing. Conclusion: Ability to discriminate between FRC-post and core is different according to color contrast. MACRO-LOCK ${ }^{\mathrm{TM}}$ POST ILLUSION ${ }^{\mathrm{TM}} \mathrm{XRO}^{\circledR}$ posts are more discriminable when temperature is lowered by air-blowing. (J Dent Rehabil Appl Sci 2015;31(2):75-85)

Key words: MACRO-LOCK ${ }^{\mathrm{TM}}$ POST ILLUSION ${ }^{\mathrm{TM}} \mathrm{XRO}^{\circledR}$ post; thermo-sensitive pigment; color difference; fiber post removal

\section{서론}

근관치료를 한 치아는 치근단병소의 발병이나 재발로 인하여 재근관 치료를 해야 할 수 있다. ${ }^{1,2}$ 비외과적 재근 관치료 시 근관 내에 포스트가 있는 경우 근관치료 도구 가 치근단 $1 / 3$ 근관과 치근단공으로 접근하기 위해서는 포스트를 제거해야 한다. 포스트 제거는 보통 어려운 과 정이며, 포스트 제거 실패 시 재근관 치료로 치유할 수 있는 치아를 발치 해야 할 수도 있다. 포스트 제거 방법

*Correspondence to: Se-Hee Park

Associate Professor, Department of Conservative Dentistry, College of Dentistry, Gangneung-Wonju National University, 7, Jukheon-gil, Gangneung, 210-702, Republic of Korea

Tel: +82-33-640-2760, Fax: +82-33-640-3103, E-mail: drendo@gwnu.ac.kr

Received: March 13, 2015/Last Revision: May 7, 2015/Accepted: May 31, 2015
에는 ultrasonic vibration을 사용하는 방법 ${ }^{3}$ 또는 포스트 removal kits를 사용하는 방법 ${ }^{4,5}$ 이 있으며 제거의 난이도 는 포스트의 종류에 따라 달라진다. 시멘트로 접착된 금 속 포스트의 제거는 종종 시간이 오래 걸리며 치근에 해 를 가할 수 있다.

1990 년에 처음 섬유강화형 레진 포스트(Fiberreinforced composite post, FRC-post)가 소개되었고 ${ }^{6}$ 최 근에는 복합레진 코어와 함께 물리적 특성 ${ }^{7,8}$ 과 심미적 이 점 ${ }^{9,10}$ 으로 널리 사용되고 있다. FRC-포스트는 제거가 쉽

Copyright(C 2015 The Korean Academy of Stomatognathic Function and Occlusion. (c) It is identical to Creative Commons Non-Commercial License. 
고 빠르다는 연구가 있다. ${ }^{11-13}$ 그러나 실제 임상에서는 $\mathrm{FRC}$-포스트를 제거할 때 복합레진 코어 또는 상아질과 의 구별이 어려워 포스트 제거가 용이하지 않을 때가 있 다. FRC-포스트를 복합레진 코어와 구별 못하는 경우 치근천공 같은 원하지 않는 상황이 발생할 수 있다.

최근 온도에 따라 색이 변하는 색소를 포함하고 있는 FRC-포스트인 MACRO-LOCK ${ }^{\mathrm{TM}}$ POST ILLUSION ${ }^{\mathrm{TM}}$ $\mathrm{XRO}^{\circledR}$ 가 개발되었다. 체온에서는 반투명 색을 나타내 다가 공기를 불거나 물을 뿌려 온도가 내려가면 size별 로 노랑, 빨강, 파랑, 초록, 검정, 흰색의 뚜렷한 색상이 나타나게 된다.

본 논문의 목적은 FRC-포스트와 복합레진 코어 가 색상차이에 따라 구별되는 정도를 비교하고 압축공기 를 불어 냉각 시 나타나는 MACRO-LOCK ${ }^{\mathrm{TM}} \mathrm{POST}$ $\mathrm{ILLUSION}^{\mathrm{TM}} \mathrm{XRO}^{\circledR}$ 색상이 주변코어와 포스트를 구별 하는데 도움이 되는지 알아보는 것이다.

\section{연구 재료 및 방법}

\section{1. 실험재료}

복합레진코어로 Luxacore ${ }^{\circledR}$ Dual Blue와 Luxacore ${ }^{\circledR}$ A3 (DMG, Hamburg, Germany), Filtek ${ }^{\text {TM }}$ Z350 A1E (3M ESPE, St Paul, MN, USA)을 사용하였다. FRC포스트로 Snowpost ${ }^{\circledR}$ (Carbotech, Ganges, France), MACRO-LOCK ${ }^{\mathrm{TM}}$ POST ILLUSION ${ }^{\mathrm{TM}} \mathrm{XRO}^{\circledR}$ (RTD, St Egreve, France), FRC Postec ${ }^{\circledR}$ Plus (Ivoclar vivadent, Scchan, Liechtenstein) 3가지를 사용 하였으며 각각 치 관부 $1 / 3$ 부위의 최대직경은 $14.0 \mathrm{~mm}, 14.5 \mathrm{~mm}, 14.5$ $\mathrm{mm}$ 였다. 각 재료의 구성성분은 Table 1,2 에 나타내었 다.

Table 1. Composition of composite resin cores

\begin{tabular}{|c|c|c|c|}
\hline Core & Shade & Resin matrix & Filler \\
\hline $\begin{array}{l}\text { Luxacore }^{\circledR} \text { Dual DMG, } \\
\text { Hamberg, Germany }\end{array}$ & $\begin{array}{c}\text { A3 } \\
\text { Blue }\end{array}$ & Bis-GMA & Barium glass $69 \%$, pyrog. silica 3\% \\
\hline Filtek $^{\mathrm{TM}}$ Z350 & A1E & $\begin{array}{l}\text { BIS-GMA, BIS-EMA, } \\
\text { UDMA with small amounts of TEGDMA }\end{array}$ & Zirconia/silica nanocluster \\
\hline
\end{tabular}

Bis-GMA, bisphenol glycidyl methacrylate; BIS-EMA, ethoxylated bisphenol A dimethacrylate; UDMA, urethanedimethacrylate; TEGDMA, triethylene glycol-glycidyl methacrylate.

Table 2. Composition of FRC-posts

\begin{tabular}{|c|c|c|c|c|}
\hline FRC-Post & Fibers & Resin matrix & Shape & Diameter* \\
\hline $\begin{array}{l}\text { Snowpost }^{\circledR} \\
\text { Abrasive Technology, Ganges, France } \\
\text { Size } 14\end{array}$ & $\begin{array}{l}\text { Zirconia-rich } \\
\text { glass }\end{array}$ & Epoxy & $\begin{array}{l}\text { Cylindrical with long } \\
\text { apical cone }\end{array}$ & $1.40 \mathrm{~mm}$ \\
\hline $\begin{array}{l}\text { MACRO-LOCKTM POST } \\
\text { ILLUSIONTM XRO }^{\circledR} \\
\text { RTD, Grenble, France } \\
\text { Size } 2\end{array}$ & Quartz & Epoxy & $\begin{array}{l}\text { Tapered, circumferential } \\
\text { head grooves, spiral head } \\
\text { serrations }\end{array}$ & $1.45 \mathrm{~mm}$ \\
\hline $\begin{array}{l}\text { FRC Postec }{ }^{\circledR} \text { Plus } \\
\text { Ivoclar-Vivadent, Schaan, Liechtenstein } \\
\text { Size } 1\end{array}$ & Glass & $\begin{array}{l}\text { UDMA,TEGDMA, } \\
\text { Highly Dispersed } \\
\text { silicon dioxide }\end{array}$ & $\begin{array}{l}\text { Yetteerbium trifluoride, } \\
\text { Tapered }\end{array}$ & $1.45 \mathrm{~mm}$ \\
\hline
\end{tabular}

*Coronal part of FRC-post.

UDMA, urethanedimethacrylate; TEGDMA, triethylene glycol-glycidyl methacrylate. 


\section{2. 시편제작}

발거한 9 개의 하악 소구치를 사용하였다. 모든 치아 는 한 개의 근관을 가진 단근치로 치근첨이 다 형성되었 고 크기와 길이는 다음과 같다. 백악법랑경계부(CEJ)에 서의 가로 직경 $5 \mathrm{~mm}( \pm 0.5 \mathrm{~mm})$, 세로 직경 $4 \mathrm{~mm}( \pm$ $0.5 \mathrm{~mm}), \mathrm{CEJ} J$ 에서 치근 끝까지의 길이 $15 \mathrm{~mm}( \pm 0.5$ $\mathrm{mm}$ )이였다. 치근단공에서 Size $10 \mathrm{~K}$-file이 보일 때의 길이보다 $1 \mathrm{~mm}$ 짧게 작업장길이를 결정하였다. 각각의 근관은 최종 taper 0.06 ISO size $40 \mathrm{ProFile}^{\circledR}$ (Dentsply Maillefer, Ballaigues, Switzerland)으로 마무리하고 taper 0.06 ISO size 40 Gutta-percha points (Diadent, Cheongwon, Korea)과 실러 AH Plus ${ }^{\circledR}$ Jet $^{\mathrm{TM}}$ (Dentsply, Konstanz, Germany)으로 근관 충전하였다. 근관형 성 후 백악법랑경계(CEJ)에서 치관 부위를 제거하고 치근의 잘린 단면은 주수하에 grinder RB209 Minipol (RandB, Seoul, Korea)에 장착한 \#600사포로 편평하게 연마하였다.

편평하게 연마된 3 개의 치근면이 편평한 유리판과 맞닿게 하였으며 치근 사이가 일정간격이 되도록 일 렬로 위치시키고 치근의 치관부위 양쪽과 치근단 부 위를 복합레진과 강선으로 고정하고 각각의 치근을
외직경 $3 \mathrm{~mm}$, 내직경 $1.5 \mathrm{~mm}$ 의 silicone tube (Hami, Seoul, Korea)로 4번씩 감았다. 고정된 치근을 $1.5 \mathrm{~mm}$ $\times 4.4 \mathrm{~mm} \times 1.5 \mathrm{~mm}$ 직육면체 틀에 치근의 치관부가 $1 \mathrm{~mm}$ 노출되게 고정하고 투명한 cold mounting resin (Technovit 2000 LC, Kulzer, Wehrheim, Germany)으로 매몰하였다. 매몰재 광중합을 위해 4개의 Lamp $(9 \mathrm{~W})$ 가 달린 220 V/60 Hz Cure box (Vision science, Bucheon, Korea)로 20 분간 광조사 하였다.

제조사 지시에 따라 근관형성 후 잘린 치근면 위로 포 스트의 길이가 $3 \mathrm{~mm}$ 가 되도록 세 종류의 $\mathrm{FRC}$-포스트 를 복합레진 시멘트(U200, 3M ESPE)로 근관내 접착 하였으며 할로겐 광중합기(XL 3000)를 이용하여 40초 간 광중합 하였다. 그 후 직경과 높이가 $6 \mathrm{~mm}$ 인 원통형 의 관을 포스트가 중앙에 오도록 고정 후 같이 매몰된 3 개의 치근 위에 같은 코어를 축조한 뒤 할로겐 광중합기 (XL 3000)를 이용하여 40초간 광중합 하였다.

코어의 높이가 $3 \mathrm{~mm}$ 가 되도록 코어 수평면을 주수 하에 Minipol에 장착한 \#600사포로 편평하게 연마하 였고 3 개의 포스트 단면은 모두 노출 시켰다. 치은 재현 을 위해 $1.5 \mathrm{~mm}$ 두께의 Gi-Mask (coltene, Altstätten, Switzerland)를 코어주변에 적용하였다(Fig. 1). 이렇게 3 종류 코어를 사용하여 3 개의 시편을 제작하였다.

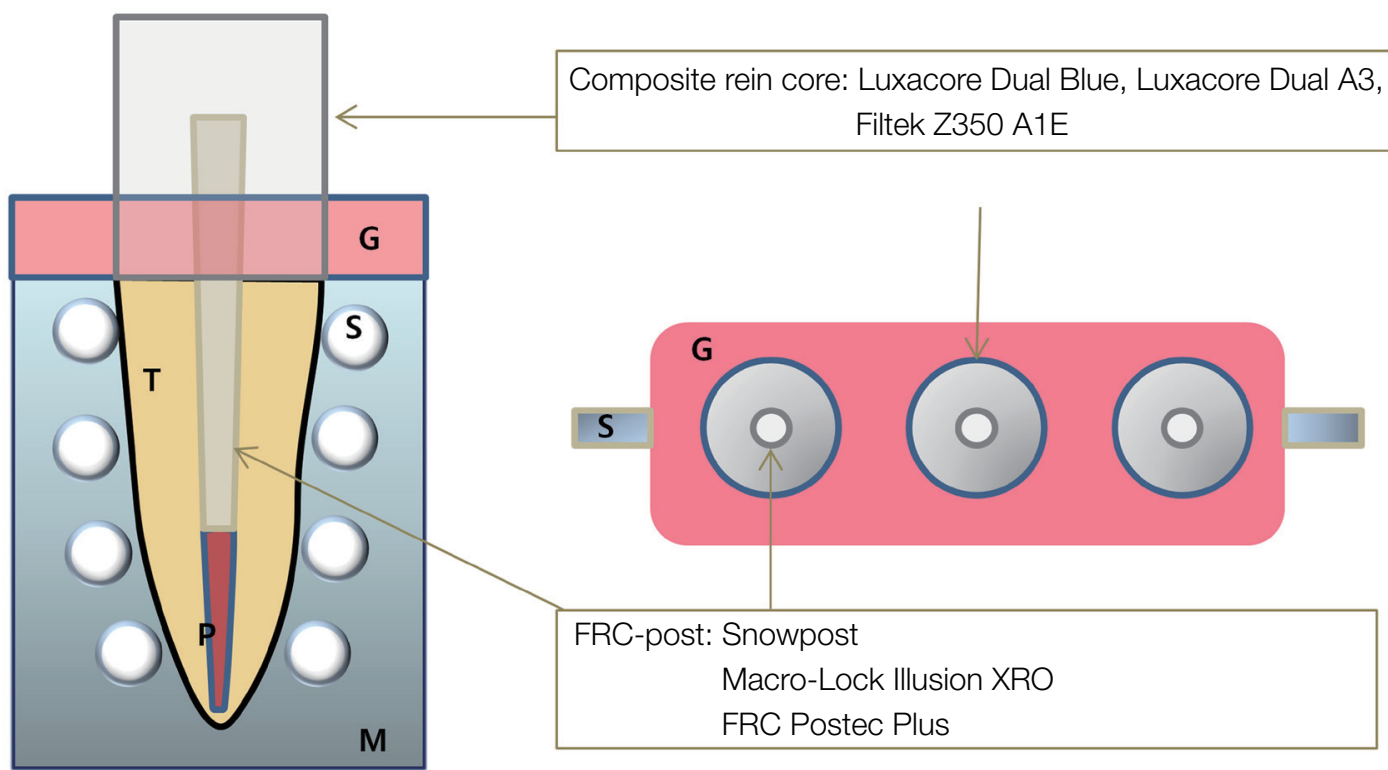

A

B

Fig. 1. Schemic drawing of specimen. (A) Longitudinal section of specimen, (B) Top view of specimen. S, silicone tube; $G$, Gi-mask; M, transparent cold mounting resin; P, Gutta-percha; T, lower premolar. 
$37^{\circ} \mathrm{C}$ 에 맞춘 항온수조기(10L, JEIO TECH, Daejeon, Korea)에 하루 동안 제작한 위의 시편과 내직경 1.6 $\mathrm{mm}$, 외직경 $5.0 \mathrm{~mm}$ 의 silicone Masterflex tube (9640014 , Masterflex, IL, USA)를 보관 하였다.

Silicone Masterflex tube의 한 쪽 끝은 항온 수조기 넣 고 한 쪽 끝은 시편의 silicone tube와 연결하였다. 그리 고 Masterflex tube를 Masterflex L/S Peristatic pump 959-225 (Masterflex, IL, USA)에 장착하여 $1000 \mathrm{~mL} /$ $\min$ 속도로 항온수조의 $37^{\circ} \mathrm{C}$ 물이 치근 주위를 흐르도 록 하여 체온을 재현하였다. 시편 silicone tube의 다른 쪽 끝은 다시 항온 수조에 넣어 항온수조기 물의 양을 일정하게 유지시켰다.

\section{3. 색 측정}

사진은 digital photo camera D90 (Nikon, Tokyo, Japan), Nikkor 105 mm AF-S Micro lens, Sigma EM140 DG ring flash로 촬영하였다. 모든 설정 값들을 일 정하게 하기 위해 카메라는 삼각대로 고정하고 시편은 테이블에 고정된 vise에 고정하였다. 확대 배율은 1.5 배 로 시편에서 카메라까지의 거리는 $250 \mathrm{~mm}$ 였다. Mode 는 “Manual", $\mathrm{F}=10.0$, 노출 시간은 1/200초, ISO 200 으로 설정하였다. 보조등으로 시편에서 10시 방향 거리 $20 \mathrm{~cm}$ 에 한 개의 $60 \mathrm{~W}$ 백열등 조명기구를 사용하였다.

사진은 치근을 감은 실리콘 튜브에 항온수조 $37^{\circ} \mathrm{C}$ 물이 흐르는 상황에서 Macro-Lock Illusion XO 포스 트표면에 three-way syringe의 압축공기를 불은 경우 와 불지 않은 경우 두 가지로 촬영하였다. 촬영된 사진 에서 $\mathrm{FRC}$-포스트 중앙 부위와 코어 우측 중앙 부위 50 $\times 50$ pixel의 평균 CIE L*a*b*를 Human eye program (PSICO, Suwon, Korea)을 이용하여 측정하였다.

측정된 코어와 포스트의 색상CIE $\mathrm{L}^{*} \mathrm{a} * \mathrm{~b} *$ 값으로 색 상차이 $(\Delta \mathrm{E})$ 를 구하여 비교하였으며 공식은 아래와 같 다.

$$
\Delta \mathrm{E}=\left[\left(\mathrm{L}_{1}-\mathrm{L}_{2}\right)^{2}+\left(\mathrm{a}_{1}-\mathrm{a}_{2}\right)^{2}+\left(\mathrm{b}_{1}-\mathrm{b}_{2}\right)^{2}\right]^{1 / 2}
$$

CIE L*a*b* scale은 Adams-Nickersman space의 단순 화된 제곱근의 변형으로 삼차원의 색공간에 색을 나타 낼 수 있는 좌표로써 측색기로 계측된 3자극치 XYZ 값 으로부터 산출된 $\mathrm{L}^{*}, \mathrm{a}^{*}$ 그리고 $\mathrm{b}^{*}$ 값에 의한 3 차원 직교 좌표를 이용한다. 이러한 CIE L*a*b* scale에서 L*은 밝 기(lightness)를 나타내며 L*값이 100이면 완전한 백색, 0 은 검정색을 나타낸다. $\mathrm{a}^{*}$ 와 $\mathrm{b} *$ 는 색도(Chromaticity)
를 나타내며 $a^{*}$ 값이 (+)이면 적색, (-)이면 녹색을 나타 내며, $\mathrm{b}^{*}$ 값이 (+)이면 황색, (-)이면 청색을 나타낸다. ${ }^{14}$

\section{4. 설문조사}

강릉원주대학교 치과병원에 재직중인 치과의사 50 명 과 치과대학 재학생 50 명 총 100 명에게 시편을 촬영한 사진을 띄운 65인치 TV-monitor LG 65LM6200 (LG Electronics Inc, Seoul, Korea)를 보고 코어 별로 가장 구 별이 쉬운 포스트를 선택하게하였고 MACRO-LOCK ${ }^{\mathrm{TM}}$ POST ILLUSION $^{\mathrm{TM}} \mathrm{XRO}^{\circledR}$ 가 압축 공기를 불었을 때 구별이 더 용이한지를 조사하였다. 그 포스트를 선택한 명수를 백분율로 계산하였다.

$$
\%=\frac{(\text { 그 포스트를 선택한 명수 })}{(100 \text { [50명 치과의사 }+50 \text { 명 치과대학생 }])}
$$

\section{5. 계면 및 단면 관찰}

Resin 코어가 FRC-post별로 어떻게 구별되는 지를 자 세히 관찰하고 MACRO-LOCK ${ }^{\mathrm{TM}}$ POST ILLUSION ${ }^{\mathrm{TM}}$ $\mathrm{XRO}^{\circledR}$ 의 색상변화의 원인을 관찰하기 위하여 확대 관 찰하기로 하였다. Snowpost ${ }^{\circledR}$ 와 FRC Postec ${ }^{\circledR}$ Plus 포 스트를 투명한 cold mounting resin으로 매몰하고 MACRO-LOCK ${ }^{\mathrm{TM}}$ POST ILLUSION ${ }^{\mathrm{TM}} \mathrm{XRO}^{\circledR}$ 는 압 축 공기를 불었을 때 색이 더 잘 보이게 해주는 Filtek ${ }^{\mathrm{TM}}$ $\mathrm{Z} 350 \mathrm{~A} 1 \mathrm{E}$ 으로 매몰한 뒤 주수하에 \#600, \#1000, \#1500, \#2000 사포로 연마한 횡단면을 Leica DFC 290 digital camera가 달린 Leica MZ125 microscope (Leica, Heerbrugg, Germany)으로 100배 배율로 관찰하였 다. 그리고 추가적으로 Olympus DP70 digital camera 가 달린 Olympus BX50 microscope (Olympus, Tokyo, Japan)으로 종단면을 40배 배율로 관찰하였으며 좀 더 색상차이가 분명히 들어나는 MACRO-LOCK ${ }^{\mathrm{TM}}$ POST ILLUSION $^{\mathrm{TM}} \mathrm{XRO}^{\circledR}$ size 5 (color black)을 사용하였다.

\section{결과}

코어와 FRC-포스트의 평균 CIE L*a*b*는 Table 3, 4, 5 에 나타내었다. 복합레진 코어와 FRC-포스트의 측정 된 평균 색상 $\mathrm{CIE} \mathrm{L*a*b*값과} \mathrm{색상차이}(\Delta \mathrm{E})$, 가장 구 별이 잘되는 포스트를 선택한 백분율(\%)은 Table 6에 나타내었다. MACRO-LOCK ${ }^{\mathrm{TM}}$ POST ILLUSION ${ }^{\mathrm{TM}}$ 
Table 3. Mean CIE $\mathrm{L}^{*} \mathrm{a}^{*} \mathrm{~b}^{*}$ of composite resin core and Snowpost ${ }^{\circledR}$ and color difference $(\Delta \mathrm{E})$ between composite resin core and Snowpost ${ }^{\mathbb{B}}$

\begin{tabular}{|c|c|c|c|c|c|c|c|c|}
\hline & & \multicolumn{3}{|c|}{ Core } & \multicolumn{3}{|c|}{ Snowpost $^{\circledR}$} & \multirow[b]{2}{*}{$\Delta \mathrm{E}$} \\
\hline & & $\mathrm{L}^{*}$ & $a^{*}$ & $\mathrm{~b}^{*}$ & $\mathrm{~L}^{*}$ & $a^{*}$ & $b^{*}$ & \\
\hline \multirow[t]{3}{*}{$37^{\circ} \mathrm{C}$} & Luxacore $^{\circledR}$ Blue & 59.4 & 8.5 & -14.3 & 84.0 & 6.8 & 2.3 & 29.7 \\
\hline & Luxacore $^{\circledR}$ A3 & 76.4 & 11.1 & 17.3 & 86.5 & 7.9 & 7.2 & 14.7 \\
\hline & Z350 A1E & 79.5 & 9.2 & 7.1 & 85.3 & 7.6 & 6.7 & 6.0 \\
\hline \multirow[t]{3}{*}{ Air* } & Luxacore $^{\circledR}$ Blue & 59.7 & 8.5 & -14.5 & 84.9 & 6.8 & 2.1 & 30.1 \\
\hline & Luxacore $^{\circledR}$ A3 & 75.8 & 11.3 & 17.4 & 86.0 & 7.9 & 7.3 & 14.8 \\
\hline & Z350 A1E & 79.3 & 9.2 & 7.5 & 85.1 & 7.6 & 6.7 & 6.1 \\
\hline
\end{tabular}

Air*, temperature is lowered by air-blowing.

Table 4. Mean CIE L*a*b* of composite resin core and MACRO-LOCK ${ }^{\mathrm{TM}}$ POST ILLUSION $^{\mathrm{TM}}$ XRO $^{\circledR}$ post and color difference $(\Delta \mathrm{E})$ between composite resin core and MACRO-LOCK ${ }^{\mathrm{TM}}$ POST ILLUSION ${ }^{\mathrm{TM}}$ XRO $^{\circledR}$

\begin{tabular}{|c|c|c|c|c|c|c|c|c|}
\hline & & \multirow[b]{2}{*}{$\mathrm{L}^{*}$} & \multicolumn{2}{|l|}{ Core } & \multicolumn{3}{|c|}{$\begin{array}{c}\text { MACRO-LOCK }^{\mathrm{TM}} \\
\text { POST ILLUSION }^{\mathrm{TM}} \mathrm{XRO}^{\circledR}\end{array}$} & \multirow[b]{2}{*}{$\Delta \mathrm{E}$} \\
\hline & & & $a^{*}$ & $\mathrm{~b}^{*}$ & $\mathrm{~L}^{*}$ & $a^{*}$ & $\mathrm{~b}^{*}$ & \\
\hline \multirow[t]{3}{*}{$37^{\circ} \mathrm{C}$} & Luxacore $^{\circledR}$ Blue & 60.2 & 8.2 & -10.1 & 57.5 & 9.0 & 1.5 & 11.9 \\
\hline & Luxacore $^{\circledR}$ A3 & 76.2 & 11.5 & 17.7 & 63.5 & 13.3 & 16.7 & 12.9 \\
\hline & Z350 A1E & 78.4 & 9.1 & 7.9 & 63.8 & 13.4 & 14.1 & 16.4 \\
\hline \multirow[t]{3}{*}{ Air* } & Luxacore ${ }^{\circledR}$ Blue & 60.9 & 8.6 & -9.9 & 57.0 & 13.0 & 1.2 & 12.6 \\
\hline & Luxacore $^{\circledR}$ A3 & 75.2 & 13.4 & 18.1 & 60.5 & 20.8 & 16.3 & 16.6 \\
\hline & Z350 A1E & 78.1 & 10.5 & 8.2 & 61.4 & 19.4 & 14.1 & 19.8 \\
\hline
\end{tabular}

Air*, temperature is lowered by air-blowing.

Table 5. Mean CIE $\mathrm{L}^{*} \mathrm{a}^{*} \mathrm{~b}^{*}$ of composite resin core and FRC Postec ${ }^{\circledR}$ Plus post and color difference $(\Delta \mathrm{E})$ between composite resin core and FRC Postec ${ }^{\circledR}$ Plus post

\begin{tabular}{|c|c|c|c|c|c|c|c|c|}
\hline & & \multirow[b]{2}{*}{$\mathrm{L}^{*}$} & \multicolumn{2}{|l|}{ Core } & \multicolumn{3}{|c|}{ FRC Postec ${ }^{\circledR}$ Plus } & \multirow[b]{2}{*}{$\Delta \mathrm{E}$} \\
\hline & & & $a^{*}$ & $\mathrm{~b}^{*}$ & $\mathrm{~L}^{*}$ & $a^{*}$ & $\mathrm{~b}^{*}$ & \\
\hline \multirow[t]{3}{*}{$37^{\circ} \mathrm{C}$} & Luxacore $^{\circledR}$ Blue & 58.4 & 8.3 & -12.5 & 61.7 & 7.9 & 0.0 & 12.9 \\
\hline & Luxacore $^{\circledR}$ A3 & 75.5 & 11.0 & 16.4 & 69.1 & 12.0 & 14.1 & 6.9 \\
\hline & Z350 A1E & 80.5 & 9.4 & 6.7 & 72.9 & 10.2 & 11.2 & 8.9 \\
\hline \multirow[t]{3}{*}{ Air* } & Luxacore $^{\circledR}$ Blue & 59.4 & 8.7 & -12.9 & 63.8 & 8.5 & -0.7 & 13.0 \\
\hline & Luxacore ${ }^{\circledR}$ A3 & 74.7 & 11.9 & 16.8 & 67.5 & 12.2 & 16.0 & 7.3 \\
\hline & Z350 A1E & 80.7 & 9.0 & 8.0 & 73.0 & 9.7 & 11.9 & 8.7 \\
\hline
\end{tabular}

Air*, temperature is lowered by air-blowing.

$\mathrm{XRO}^{\circledR}$ 가 $37^{\circ} \mathrm{C}$ 일 때와 압축 공기를 불었을 때, 둘 중 구 별이 잘되는 경우를 선택한 백분율(\%)과 포스트의 색상 차이 $(\Delta \mathrm{E})$ 는 Table 7 에 나타내었다.

$37^{\circ} \mathrm{C}$ 에서 코어가 Luxacore ${ }^{\circledR}$ Dual Blue인 경우 97\% 의 응답자가 Snowpost ${ }^{\circledR}$ 가 구별이 가장 잘 된다고 선택
하였으며 Snowpost ${ }^{\circledR}$ 와 코어의 색상차이 $(\Delta \mathrm{E})$ 는 29.7 이었다. $37^{\circ} \mathrm{C}$ 에서 코어가 Luxacore ${ }^{\circledR}$ Dual A3인 경우 $55 \%$ 의 응답자는 Snowpost ${ }^{\circledR}$ 가 구별이 가장 잘 된다고 선택하였으며, Snowpost ${ }^{\circledR}$ 와 코어의 색상차이 $(\Delta \mathrm{E})$ 는 14.7, MACRO-LOCK ${ }^{\mathrm{TM}}$ POST ILLUSION ${ }^{\mathrm{TM}} \mathrm{XRO}^{\circledR}$ 
와 코어의 색상차이 $(\Delta \mathrm{E})$ 는 12.9 였다. $37^{\circ} \mathrm{C}$ 에서 코어가 Filtek $^{\mathrm{TM}} \mathrm{Z} 350 \mathrm{~A} 1 \mathrm{E}$ 인 경우, $92 \%$ 의 응답자가 MACROLOCK $^{\mathrm{TM}}$ POST ILLUSION ${ }^{\mathrm{TM}} \mathrm{XRO}^{\circledR}$ post가 구별이 가 장 잘 된다고 선택하였으며, MACRO-LOCK ${ }^{\mathrm{TM}} \mathrm{POST}$ $\mathrm{ILLUSION}^{\mathrm{TM}} \mathrm{XRO}^{\circledR}$ post와 코어의 색상차이 $(\Delta \mathrm{E})$ 는 16.4였다.

MACRO-LOCK ${ }^{\mathrm{TM}}$ POST ILLUSION ${ }^{\mathrm{TM}} \mathrm{XRO}^{\circledR}$ post 를 $37^{\circ} \mathrm{C}$ 로 유지하였을 때와 압축 공기를 불었을 때 의 사진 중 포스트가 더 구별이 잘되는 사진을 선택하 는 조사에는 코어가 Luxacore ${ }^{\circledR}$ Dual blue의 경우 설문 자중 $75 \%$ 가 “차이를 모르겠다" 를 선택하였고, 코어가 Luxacore ${ }^{\circledR}$ Dual A3, Filetk ${ }^{\mathrm{TM}}$ Z350 A1E의 경우에는 설 문자중 각각 $67 \%, 70 \%$ 가 압축 공기를 불었을 때 구별 이 더 잘 된다고 선택하였다. $37^{\circ} \mathrm{C}$ 와 압축 공기를 불었 을 때 MACRO-LOCK ${ }^{\mathrm{TM}}$ POST ILLUSION ${ }^{\mathrm{TM}} \mathrm{XRO}^{\circledR}$ post의 색상차이 $(\Delta \mathrm{E})$ 는 코어별로 Luxacore ${ }^{\circledR}$ Dual Blue 시 4.1, Luxacore $^{\circledR}$ Dual A3시 8.1, Z350 A1E 시 6.5였다.

100 배로 관찰한 FRC-포스트 치관부 $1 / 3$ 횡단면이 Fig. 2에 나타나있다. 투명한 fiber가 레진 기질(resin matrix)에 촘촘히 박혀있는 것이 관찰이 되었다. 모 두 glass fiber는 투명하였으나 레진 기질의 색상이 Snowpost ${ }^{\circledR}$ 는 불투명한 흰색, FRC Postec ${ }^{\circledR}$ Plus는 거 의 투명한 무색(無色)이었고 MACRO-LOCK ${ }^{\mathrm{TM}}$ POST $I_{\text {ILLUSION }}^{\mathrm{TM}} \mathrm{XRO}^{\circledR}$ 는 반투명하다 온도가 내려가면 짙은 색이 나타났다. 40 배 확대한 MACRO-LOCK ${ }^{\mathrm{TM}}$ POST ILLUSION $^{\mathrm{TM}} \mathrm{XRO}^{\circledR}$ 종단면 사진에서 온도에 따 라 색이 변하는 색소가 산재하여 존재하는 것이 관찰이 되었다(Fig. 3). $22^{\circ} \mathrm{C}$ 이하에서 이러한 색소의 색이 나타 나게 되면 투명한 fiber와 resin matrix에 색이 비쳐 전체 적으로 색상을 나타내는 것으로 여겨진다.

\section{고찰}

$37^{\circ} \mathrm{C}$ 체온을 재현하기 위해 치근을 감은 silicone tube 에 항온수조에서 나온 $37^{\circ} \mathrm{C}$ 의 물이 흐르게 하였다. 구강 내 온도와 비슷한 상황이라는 것을 MACRO-LOCK ${ }^{\mathrm{TM}}$ POST ILLUSION $^{\mathrm{TM}} \mathrm{XRO}^{\circledR}$ 를 압축 공기로 불었을 때 짙어진 색이 곧 사라져 반투명해지는 것으로 확인하

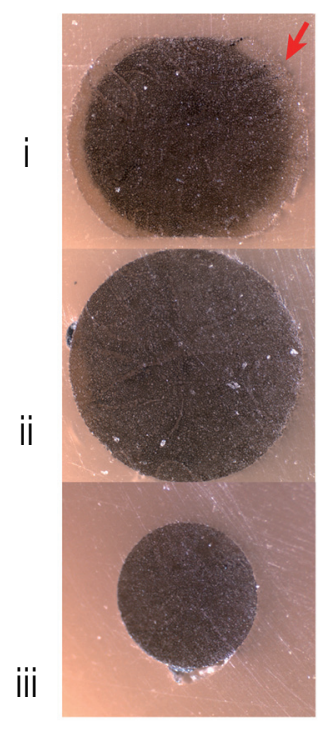

A

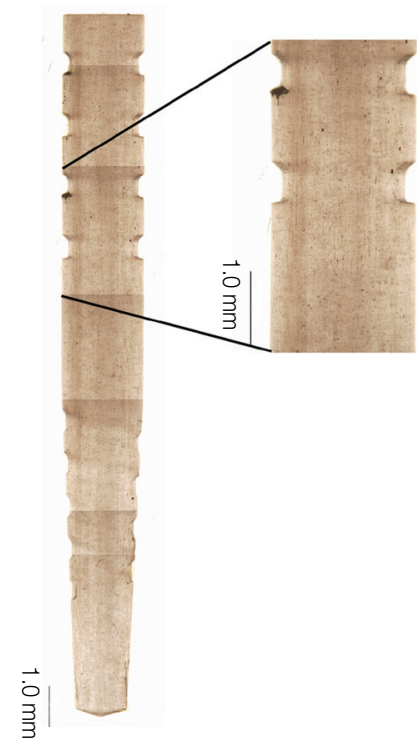

B
C
Fig. 3. Section of Macro-Lock Illusion XRO post size 5 . (A) Cross section of Macro-Lock Illusion XRO post size 5 (black thermo-sensitive pigment). i, coronal; ii, middle; iii, apical, (B) Longitudinal section of Macro-Lock Illusion XRO post size 5 (black thermo-sensitive pigment) (magnification, $\times 40$ ), (C) Extension of the part of MacroLock Illusion XRO post (magnification, $\times 40$ ).
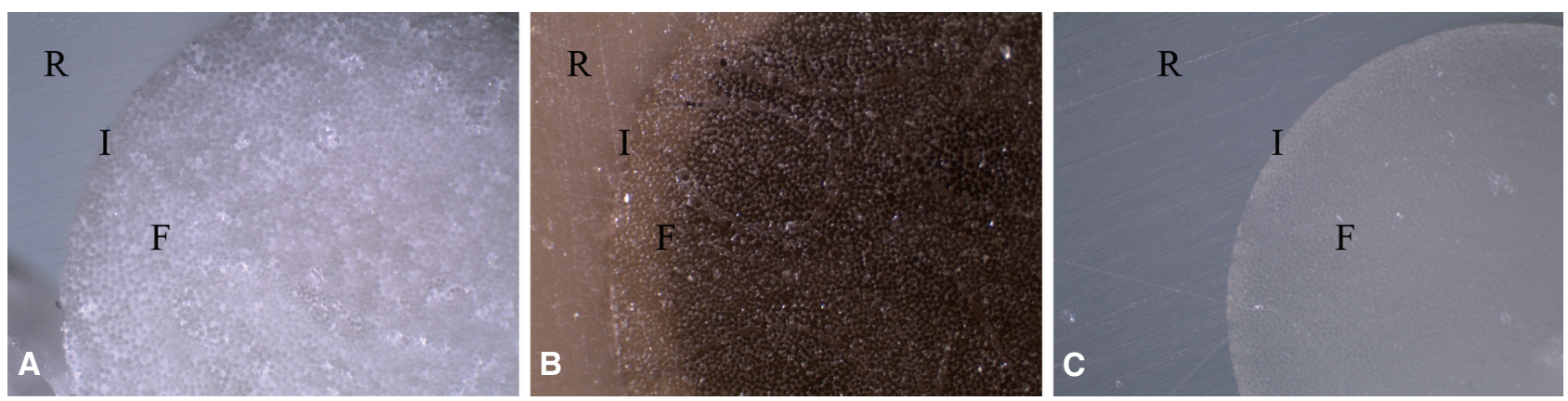

Fig 2. Cross section of FRC-posts (magnification, $\times 100$ ) (A) Snowpost, (B) Macro-Lock Illusion XRO post, (C) FRC Poestec Plus. R, resin material; I, interface between resin material and FRC-post; F, FRC-post. 
였다. 또한 치은을 재현하기 위해 Gi-Mask를 사용하 여 관찰하는 사람들의 시각이 구강 내 상황을 재현하도 록 노력하였다. FRC 포스트의 단면적 직경은 각각 1.40 $\mathrm{mm}$ (Snowpost ${ }^{\circledR}$ size 14), $1.45 \mathrm{~mm}$ (MACRO-LOCK ${ }^{\mathrm{TM}}$ POST ILLUSION $^{\text {TM }}$ XRO $^{\circledR}$ size 2), $1.45 \mathrm{~mm}$ (FRC Postec ${ }^{\circledR}$ Plus size 1)으로 비슷한 단면적을 가진 것을 사 용하였고 코어의 직경도 $6 \mathrm{~mm}$ 로 일정하게 하여 동일한 조건을 만들었다.

디지털 사진은 같은 높이, 같은 거리, 같은 각도, 같은 조명하에 같은 사진기로 촬영하였으며, 같은 공간 같은 모니터의 화면을 $4 \mathrm{~m}$ 의 동일한 거리에서 보게 하였다. 모니터 화면에 다른 물체가 비쳐 보이지 않도록 불을 끈 상태였다. 이렇게 디지털 카메라, 모니터 등에 따른 변 수 $^{14}$ 를 가능한 줄여 동일한 조건에서 색상차이에 의해서 만 복합레진 코어와 FRC-포스트를 구별하도록 하였다.

색상차이에 따라 FRC-포스트가 복합레진 코어와 구 별되는 정도를 비교하는 것이 목적이었다. 결과는 복 합레진 코어 색상에 따라 구별이 잘되는 FRC-포스트 는 달랐다. 색상차이 $(\Delta \mathrm{E})$ 가 클수록 구별이 잘 되었다. Luxacore ${ }^{\circledR}$ Dual Blue에서는 Snowpost ${ }^{\circledR}$ 가, Luxacore ${ }^{\circledR}$ Dual A3에서는 Snowpost ${ }^{\circledR}$ 가, Filtek ${ }^{\mathrm{TM}}$ Z350 A1E에서 는 MACRO-LOCK ${ }^{\mathrm{TM}}$ POST ILLUSION ${ }^{\mathrm{TM}} \mathrm{XRO}^{\circledR}$ 가 가장 구별이 잘 되었다.

구별이 가장 잘된다고 선택한 FRC-포스트의 경우 색 상차이 $(\Delta \mathrm{E})$ 의 범위가 12.9 - 30.1이었으며, 색상차이 $(\Delta \mathrm{E})$ 의 범위가 6.0 - 8.9인 경우는 거의 선택을 받지 못 하였다. 다만 MACRO-LOCK ${ }^{\mathrm{TM}}$ POST ILLUSION ${ }^{\mathrm{TM}}$ $\mathrm{XRO}^{\circledR}$ 와 FRC Postec ${ }^{\circledR}$ Plus 포스트는 Luxacore ${ }^{\circledR}$ Dual Blue와 11.9 - 13.0 범위의 색상차이 $(\Delta \mathrm{E})$ 를 나타내었으
나 Snowpost ${ }^{\circledR}$ 와 Luxacore ${ }^{\circledR}$ Dual Blue의 색상차이 $(\Delta \mathrm{E})$ 가 29.7과 30.1로 2배 이상 커 거의 선택 받지 못하였다 (Table 6).

투명도(Translucency)는 아래 배경색을 빛이 투과하 여 보이게 하는 정도를 뜻한다..$^{15}$ 1995년 Johnston 등 은 법랑질의 투명성을 재현하기 위해 $13 \mathrm{~mm}$ 두께의 복 합레진 시편을 제작하여 이 시편을 검정색 배경과 흰 색 배경에서 색을 측정하여 색상차이를 Translucency Parameter (TP)로 정의하고 비교하였다. ${ }^{16}$ 투명도가 높 을수록 배경색을 잘 투영시켰고 투명도가 낮을수록, 즉 불투명 (opacity)할 수록 배경색을 차단하였다. ${ }^{16,17}$

앞서 기술한 Snowpost ${ }^{\circledR}$ 와 Luxacore ${ }^{\circledR}$ Dual Blue의 색 상차이 $(\triangle \mathrm{E})$ 가 MACRO-LOCK ${ }^{\mathrm{TM}}$ POST ILLUSION ${ }^{\mathrm{TM}}$ $\mathrm{XRO}^{\circledR}$ 와 FRC Postec ${ }^{\circledR}$ Plus 포스트보다 2배 이상 큰 것 은 반투명한 MACRO-LOCK ${ }^{\mathrm{TM}}$ POST ILLUSION ${ }^{\mathrm{TM}}$ $\mathrm{XRO}^{\circledR}$ 와 FRC Postec ${ }^{\circledR}$ Plus 포스트는 배경색인 코어의 색을 비교적 잘 투영시켜 보이나 불투명한 Snowpost ${ }^{\circledR}$ 는 코어 색을 잘 투영시키지 않기 때문으로 생각된다. 즉Snowpost ${ }^{\mathbb{R}}$ 는 불투명하여 상대적으로 고정된 색CIE $\mathrm{L}^{*} \mathrm{a}^{*} \mathrm{~b}^{*}$ 값 $^{16}$ 을 가지고 있어 코어와의 색상차이 $(\Delta \mathrm{E})$ 가 그대로 나타나나, 반투명한 MACRO-LOCK ${ }^{\mathrm{TM}}$ POST ILLUSION $^{\mathrm{TM}} \mathrm{XRO}^{\circledR}$ 와 FRC Postec ${ }^{\circledR}$ Plus 포스트는 코 어의 색을 잘 투영시켜 코어색상에 따라 포스트의 CIE $\mathrm{L}^{*} \mathrm{a}^{*} \mathrm{~b}$ 값이 변하기 때문에 색상차이 $(\Delta \mathrm{E})$ 변화가 상대 적으로 작다. 복합레진 코어의 색상에 따라 포스트의 삼 자극치(tristimulus value) $\mathrm{L}^{*}, \mathrm{a}^{*}, \mathrm{~b}$ *가 각각 증가하거나 감소하는 경향이 관찰되며 Snowpost ${ }^{\circledR}$ 의 $\mathrm{CIE} \mathrm{L*a*b*}$ 변화는 상대적으로 작은 것이 관찰된다(Table $3,4,5)$. 3 개의 FRC-포스트 중 가장 빛을 잘 투과시키는 FRC

Table 6. Color difference $(\Delta \mathrm{E})$ between composite resin core and FRC-post when MACRO-LOCK ${ }^{\mathrm{TM}}$ POST ILLUSION ${ }^{\mathrm{TM}}$ $\mathrm{XRO}^{\circledR}$ post was at $37^{\circ} \mathrm{C}$ and by air-blowing. Percentage (\%) of people who choose the FRC-post which is the most distinguishable from composite resin core

\begin{tabular}{|c|c|c|c|c|c|c|c|}
\hline & & \multicolumn{2}{|c|}{ Snowpost ${ }^{\mathbb{B}}$} & \multicolumn{2}{|c|}{ MACRO-LOCK ${ }^{\mathrm{TM}}$} & \multicolumn{2}{|c|}{ FRC Postec ${ }^{\mathbb{B}}$} \\
\hline & & $\%$ & $\Delta \mathrm{E}$ & $\%$ & $\Delta \mathrm{E}$ & $\%$ & $\Delta \mathrm{E}$ \\
\hline \multirow[t]{3}{*}{$37^{\circ} \mathrm{C}$} & Luxacore $^{\circledR}$ Blue & 97 & 29.7 & 3 & 11.9 & 0 & 12.9 \\
\hline & Luxacore $^{\circledR}$ A3 & 55 & 14.7 & 42 & 12.9 & 3 & 6.9 \\
\hline & Z350 A1E & 10 & 6.0 & 88 & 16.4 & 2 & 8.9 \\
\hline \multirow[t]{3}{*}{ Air* } & Luxacore $^{\circledR}$ Blue & 93 & 30.1 & 6 & 12.6 & 1 & 13.0 \\
\hline & Luxacore $^{\circledR}$ A3 & 50 & 14.8 & 46 & 16.6 & 4 & 7.3 \\
\hline & Z350 A1E & 5 & 6.1 & 92 & 19.8 & 3 & 8.7 \\
\hline
\end{tabular}

Air*, temperature is lowered by air-blowing. 
$\operatorname{Postec}^{\circledR}$ Plus $^{18}$ 는 주변 코어 색에 영향을 상대적으로 많 이 받아 Luxacore ${ }^{\circledR}$ Dual blue를 제외하고 코어와의 색 상차이 $(\Delta \mathrm{E})$ 가 가장 작기에 구별이 잘 되는 포스트로 선 택 또한 거의 받지 못하였다. Snowpost ${ }^{\circledR}$ 는 불투명하여 구별이 쉬운 경우도 있으나 포스트를 접착하는 시멘트 가 자가중합이 아닌 이원중합이나 광중합형인 경우 빛 투과를 잘 못 시켜 접착에 불리 할 수 있다. ${ }^{18}$

Snowpost ${ }^{\circledR}$ 가 불투명해 구별이 잘 된다는 장점은 같 은 흰색 계열 코어에서는 많이 약해지는 것으로 보인다. Snowpost ${ }^{\circledR}$ 는 Luxacore ${ }^{\circledR}$ Dual A3에서 $50-55 \%$ 의 선택 을 받았으나 Filtek ${ }^{\mathrm{TM}} \mathrm{Z} 350$ A1E에서는 색상차이 $(\Delta \mathrm{E})$ 가 가장 작아져 설문자의 $5-10 \%$ 만이 구별이 가장 잘 된다고 선택하였다. 반대로 MACRO-LOCK ${ }^{\mathrm{TM}}$ POST ILLUSION $^{\mathrm{TM}} \mathrm{XRO}^{\circledR}$ 는 Filtek ${ }^{\mathrm{TM}} \mathrm{Z} 350 \mathrm{~A} 1 \mathrm{E}$ 에서 색상차 이 $(\Delta \mathrm{E})$ 가 더 커져 설문자중 $88-92 \%$ 가 구별이 가장 잘 된다고 선택하였다.

FRC-포스트의 색상 변화 기술은 재근관치료 시 포스 트제거에 도움이 될 수 있으며 치근단 병소의 재발이나 발생에 의해 재근관치료는 어느 정도 필요한 것으로 알 려져 있다. ${ }^{19-20} \mathrm{Abbot}^{21}$ 은 재근관치료 환자의 $1 / 3$ 에서 근 관내 포스트를 제거했다고 보고하였다. Grandini ${ }^{22}$ 도 이 러한 경우가 최근 metal 포스트나 fiber 포스트가 널리 사용됨에 따라 증가하였다고 보고 하였다.

포스트가 식립 된 치아 재근관 치료 시, 포스트 제거 는 매우 어려운 과정이며 실패할 수 있다. ${ }^{11} \mathrm{FRC}$-포스 트 제거는 포스트 방향을 따라서 포스트를 통째로 삭제 하여야 한다. MACRO-LOCK ${ }^{\mathrm{TM}}$ POST ILLUSION ${ }^{\mathrm{TM}}$ $\mathrm{XRO}^{\circledR}$ 는 평행한 fiber가 레진 기질 안에 들어있다. 평행 한 fiber는 제거용 drill이나 bur가 포스트 안에 위치 되 도록 도와주어 치근천공(root perforation)의 위험성을 줄여주며 특별한 장비가 이에 맞게 개발되었다. ${ }^{23}$

FRC-포스트의 첫 세대는 carbon-based였다. ${ }^{24}$ 색상 은 검정이었기 때문에 치아 조직과 쉽게 구별되었다. 그
러나 심미적인 요구에 의해 개발된 FRC-포스트는 근관 내에서 구별하는 것이 직관적이지 않다. ${ }^{23}$ 이러한 심미 적인 FRC-포스트의 치아와 비슷한 색상은 재근관치료 시 단점이 될 수 있다. 이러한 이유로 thermo-sensitive pigment를 포함한 fiber 포스트가 최근에 개발되었다. 체온에서는 보통의 반투명한 $\mathrm{FRC}$-포스트이지만 $22^{\circ} \mathrm{C}$ 이하에서는 size별로 노랑, 빨강, 파랑, 초록, 검정, 흰색 의 뚜렷한 색상이 나타나게 된다. $22^{\circ} \mathrm{C}$ 이하의 온도는 물을 뿌리거나 바람을 불어 얻을 수 있다.

MACRO-LOCK ${ }^{\mathrm{TM}}$ POST ILLUSION ${ }^{\mathrm{TM}} \mathrm{XRO}^{\circledR}$ 의 $37^{\circ} \mathrm{C}$ 일 때 사진과 압축 공기를 불었을 때 사진 중 구 별이 더 잘되는 사진을 선택하는 조사에서 Luxacore ${ }^{\circledR}$ Dual Blue에서는 압축 공기를 불기 전과 후 포스트 자 체의 색상차이 $(\Delta \mathrm{E})$ 값이 색 변화를 알 수 있는 $3.3^{25,26,27}$ 보다 큰 4.1 이었으나 구별하는데 차이를 모르겠다라는 응답자가 $75 \%$ 였다(Table 7). 이는 포스트자체의 색상 은 변하였으나 Luxacore ${ }^{\circledR}$ Blue와의 색 차이가 11.9에 서 12.6으로 단지 0.7 만 증가하였기 때문으로 생각된다 (Table 6). Luxacore ${ }^{\circledR}$ Dual A3와 Filtek ${ }^{\mathrm{TM}} \mathrm{Z} 350$ A1E에 서는 압축 공기를 불기전과 후 포스트의 색상차이 $(\Delta \mathrm{E})$ 가 각각 8.1 과 6.5 로 각각 설문자의 $67 \%, 70 \%$ 가 압축 공 기를 불어 변한 색으로 인하여 구별이 더 잘 된다고 하 였다(Table 7). 코어가 Luxacore ${ }^{\circledR}$ Dual A3와 Filtek ${ }^{\text {TM }}$ $\mathrm{Z} 350 \mathrm{~A} 1 \mathrm{E}$ 일 때는 압축 공기를 불어 나타난 MACROLOCK $^{\mathrm{TM}}$ POST ILLUSION ${ }^{\mathrm{TM}} \mathrm{XRO}^{\circledR}$ 의 붉은 색이 포 스트와 코어의 구별에 도움이 되는 것으로 판단된다.

압축 공기를 불은 경우 MACRO-LOCK ${ }^{\mathrm{TM}}$ POST ILLUSION ${ }^{\mathrm{TM}} \mathrm{XRO}^{\circledR}$ 의 CIE L*a*b* 삼자극치(tristimulus value)중 $\mathrm{L}^{*}$ 과 $\mathrm{b} *$ 는 거의 변화가 없었으나 $\mathrm{a} *$ 값이 $45-56 \%$ 증가하여 붉은 색이 짙어졌다(Table 4). 또 한 MACRO-LOCK ${ }^{\mathrm{TM}}$ POST ILLUSION ${ }^{\mathrm{TM}} \mathrm{XRO}^{\circledR}$ 가 가장 구별이 잘된다고 선택하는 설문자의 백분율 과 MACRO-LOCK ${ }^{\mathrm{TM}}$ POST ILLUSION ${ }^{\mathrm{TM}} \mathrm{XRO}^{\circledR}$

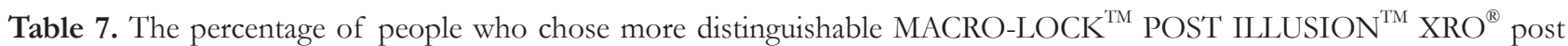
between at $37^{\circ} \mathrm{C}$ and by air-blowing. The color difference $(\Delta \mathrm{E})$ of MACRO-LOCK ${ }^{\mathrm{TM}}$ POST ILLUSION $^{\mathrm{TM}} \mathrm{XRO}^{\circledR}$ post $^{\circ}$ between at $37^{\circ} \mathrm{C}$ and by air-blowing

\begin{tabular}{|c|c|c|c|c|}
\hline \multicolumn{5}{|c|}{ MACRO-LOCK $^{\text {TM }}$ POST ILLUSION ${ }^{\text {TM }}$ XRO $^{\mathbb{B}}$} \\
\hline Core & $37^{\circ} \mathrm{C}$ & Air blowing & No difference & $\Delta \mathrm{E}$ \\
\hline Luxacore $^{\circledR}$ Blue & $3 \%$ & $22 \%$ & $75 \%$ & 4.1 \\
\hline Luxacore $^{\circledR}$ A3 & $17 \%$ & $67 \%$ & $16 \%$ & 8.1 \\
\hline Z350 A1E & $6 \%$ & $70 \%$ & $24 \%$ & 6.5 \\
\hline
\end{tabular}


와 코어의 색상차이 $(\Delta \mathrm{E})$ 는 MACRO-LOCK ${ }^{\mathrm{TM}}$ POST $\mathrm{ILLUSION}^{\mathrm{TM}} \mathrm{XRO}^{\circledR}$ 를 압축 공기로 불은 경우 조금 증 가하였다(Table 4, 6).

Fig. 3(a)-i 치관부 1/3 Macro-Lock Illusion XRO 횡단면을 보면 투명한 변연이 관찰이 된다. 이는 치관 부 $1 / 3$ 에서는 pigment가 주로 중심에 존재하는데 평행 한 glass fiber가 빛을 평행하게 투과시키는 특성에 의해 pigment의 색이 중심에만 비쳐 보이고 pigment가 거의 없는 변연 부위는 투명하게 보이는 걸로 생각된다. 이러 한 MACRO-LOCK ${ }^{\mathrm{TM}}$ POST ILLUSION ${ }^{\mathrm{TM}} \mathrm{XRO}^{\circledR}$ 의 치관부 $1 / 3$ 의 투명한 변연은 복합레진 코어와의 경계를 구별하는데 어려움을 줄 수 있다. 중앙부와 치근단 $1 / 3$ 부위를 관찰하면 색소가 고르게 퍼져있어 투명한 가장 자리가 관찰이 되지 않는다(Fig. 3(a)- ii, iii).

이번 연구에서는 여섯 가지 색을 나타내는 MACROLOCK $^{\mathrm{TM}}$ POST ILLUSION ${ }^{\mathrm{TM}} \mathrm{XRO}^{\circledR}$ 중 붉은색의 size 2 대해서만 연구하였다. 복합레진 코어 색상에 따라 구 별이 잘되는 FRC-포스트의 색이 다를 수 있으므로 다 른 size의 다른 색에 대해서도 추가적인 연구가 필요 할 것으로 생각된다. 응답자들이 시편을 직접 보지 못하고 TV-monitor를 보고 선택하게 한 것은 실험의 편의성을 위한 것으로 이번 실험은 실제 임상 상황과는 다를 수 있는 한계를 가지고 있다.

\section{결론}

본 연구에서는 복합레진 코어와 FRC-포스트가 색 상 차이에 따라 구별되는 정도를 비교하였고 압축공 기를 불었을 때 나타나는 MACRO-LOCK ${ }^{\mathrm{TM}}$ POST ILLUSION $^{\mathrm{TM}} \mathrm{XRO}^{\circledR}$ post 색상이 주변 복합레진 코어 와의 구별에 도움이 되는지를 알아보았으며 결과는 아 래와 같다.

1. 복합레진 코어와 FRC-포스트는 색상차이 $(\Delta \mathrm{E})$ 에 따라 구별되는 정도는 달랐다. 즉, 코어 색상에 따 라 구별이 가장 잘되는 FRC-포스트는 달랐다.

- Luxacore ${ }^{\circledR}$ Dual Blue의 경우 Snowpost ${ }^{\circledR}$ 가 가장 구별이 잘되었다.

- Luxacore ${ }^{\circledR}$ Dual A3의 경우 Snowpost ${ }^{\circledR}$ 가 가장 구별이 잘되었다.

- Filtek ${ }^{\mathrm{TM}}$ Z350 A1E의 경우 MACRO-LOCK ${ }^{\mathrm{TM}}$ $\mathrm{POST} \mathrm{ILLUSION}^{\mathrm{TM}} \mathrm{XRO}^{\circledR}$ 가 가장 구별이 잘되 었다.
2. 코어가 Luxacore ${ }^{\circledR}$ Dual A3 또는 Filtek ${ }^{\mathrm{TM}} \mathrm{Z} 350$ $\mathrm{A} 1 \mathrm{E}$ 일 때 온도가 내려가면 나타나는 MACROLOCK $^{\mathrm{TM}}$ POST ILLUSION ${ }^{\mathrm{TM}} \mathrm{XRO}^{\circledR}$ size 2 의 붉 은 색은 주변 코어와의 구별을 용이하게 한다.

\section{Acknowledgements}

이 논문은 2012학년도 강릉원주대학교 장기해외파견 연구지원에 의하여 수행되었음.

\section{Orcid}

Jou-Hwe Kim http://orcid.org/0000-0001-7307-4252

Jin-Woo Kim http://orcid.org/0000-0002-0004-0710

Kyung-Mo Cho http://orcid.org/0000-0003-3464-9425

Se-Hee Park http://orcid.org/0000-0002-4052-4082

\section{References}

1. Sjögren U, Figdor D, Persson S, Sundqvist G. Influence of infection at the time of root filling on the outcome of endodontic treatment of teeth with apical periodontitis. Int Endod J 1997;30:297-306.

2. Strindberg LZ. The dependence of the results of pulp therapy on certain factors. An analytic study based on radiographic and clinical followup examinations. Acta Odont Scand 1956;14(Suppl 21):1-175.

3. Dixon EB, Kaczkowski PJ, Nicholls JI, Harrington GW. Comparison of two ultrasonic instruments for post removal. J Endod 2002;28:111-5.

4. Stamos DE, Gutmann JL. Survey of endodontic retreatment methods used to remove intraradicular posts. J Endod 1993;19:366-9.

5. Lindemann M, Yaman P, Dennison JB, Herrero AA. Comparison of the efficiency and effectiveness of various techniques for removal of fiber posts. J Endod 2005;31:520-2.

6. Duret B, Reynaud M, Duret F. A new concept of corono-radicular reconstruction, the Composipost (2). Chir Dent Fr 1990;60:69-77.

7. Reid LC, Kazemi RB, Meiers JC. Effect of fatigue testing on core integrity and post microleakage of teeth restored with different post systems. J Endod 


$$
\text { 2003;29:125-31. }
$$

8. Eskitaşcioğlu G, Belli S, Kalkan M. Evaluation of two post core systems using two different methods (fracture strength test and a finite elemental stress analysis). J Endod 2002;28:629-33.

9. Martelli R. Fourth-generation intraradicular posts for the aesthetic restoration of anterior teeth. Pract Periodontics Aesthet Dent 2000;12:579-84; quiz 586-8.

10. Quintas AF, Dinato JC, Bottino MA. Aesthetic posts and cores for metal-free restoration of endodontically treated teeth. Pract Periodontics Aesthet Dent 2000;12:875-84; quiz 886.

11. Gesi A, Magnolfi S, Goracci C, Ferrari M. Comparison of two techniques for removing fiber posts. J Endod 2003;29:580-2.

12. Anderson GC, Perdigão J, Hodges JS, Bowles WR. Efficiency and effectiveness of fiber post removal using 3 techniques. Quintessence Int 2007;38:66370 .

13. Frazer RQ, Kovarik RE, Chance KB, Mitchell RJ. Removal time of fiber posts versus titanium posts. Am J Dent 2008;21:175-8.

14. Park SJ, Lee HY, Nah MY, Chang HS, Hwang YC, Oh WM, Hwang IN. The evaluation of color and color difference according to the layering placement of Incisal shade composites on the body composites of the indirect resin restoration. J Korean Acad Conserv Dent 2011;36:37-49.

15. Yu B, Ahn JS, Lee YK. Measurement of translucency of tooth enamel and dentin. Acta Odontol 2009;67:57-64.

16. Johnston WM, Ma T, Kienle BH. Translucency parameter of colorants for maxillofacial prostheses. Int J Prosthodont 1995;8:79-86.

17. Ryan EA, Tam LE, McComb D. Comparative translucency of esthetic composite resin restorative materials. J Can Dent Asso 2010;76:a84.

18. Goracci C, Corciolani G, Vichi A, Ferrari M. Lighttransmitting ability of marketed fiber posts. J Dent Res 2008;87:1122-6.

19. Sjögren U, Hägglund B, Sundqvist G, Wing K. Factors affecting the long-term results of endodontic treatment. J Endod 1990;16:498-504.

20. Tronstad L, Asbjørnsen K, Døving L, Pedersen I, Eriksen HM. Influence of coronal restorations on the periapical health of endodontically treated teeth. Endod Dent Traumatol 2000;16:218-21.

21. Abbott PV. Analysis of a referral-based endodontic practice: part 2. treatment provided. J Endod 1994; 20:253-7.

22. Ferrari M. Introduction. In: Ferrari M, Breschi L, Grandini S, editors. Fiber posts and endodontically treated teeth: a compendium of scientific and clinical perspectives. Wendywood; Modern Dentistry Media; 2008. p. 9-13.

23. de Rijk WG. Removal of fiber posts from endodontically treated teeth. Am J Dent 2000;13: 19B-21B.

24. Torbjörner A, Karlsson S, Syverud M, Hensten Pettersen A. Carbon fiber reinforced root canal posts. Mechanical and cytotoxic properties. Eur J Oral Sci 1996;104:605-11.

25. Vichi A, Ferrari M, Davidson CL. Color and opacity variations in three different resin-based composite products after water aging. Dent Mater 2004;20: 530-4.

26. Vichi A, Louca C, Corciolani G, Ferrari M. Color related to ceramic and zirconia restorations: a review. Dent Mater 2011;27:97-108.

27. Ragain JC, Johnston WM. Color acceptance of direct dental restorative materials by human observers. Color Res Appl 2000;25:278-85. 


\section{색상차이에 따른 FRC-포스트와 코어 사이의 구별}

\section{김주회, 김진우, 조경모, 박세희*}

강릉원주대학교 치과대학 치과보존학교실

목적: 이번 연구의 목적은 FRC-포스트와 코어가 색상차이에 따라 구별되는 정도를 비교하는 것이다.

연구 재료 및 방법 : 실험을 위해 유사한 크기 $( \pm 0.5 \mathrm{~mm})$ 와 길이 $( \pm 0.5 \mathrm{~mm})$ 의 발치 한 하악 소구치 9 개를 근관 형성하고 충전하였다. 3 개의 치근을 체온을 재현하기 위해 $37^{\circ} \mathrm{C}$ 물이 흐르는 가는 실리콘 튜브로 감은 후 cold mounting resin에 매몰하여 각 3 개의 치근이 매몰된 총 3 개의 시편을 제작하였다. 개개의 시편 치근에는 3 종류의 Snowpost ${ }^{\circledR}$, MACROLOCK $^{\mathrm{TM}}$ POST ILLUSION ${ }^{\mathrm{TM}} \mathrm{XRO}^{\circledR}$, FRC Postec ${ }^{\circledR}$ Plus post를 이용하여 각각의 포스트에 맞게 공간을 형성하고 포 스트를 접착하였다. 3 개의 시편 별로 Luxacore ${ }^{\circledR}$ Dual Blue, Luxacore ${ }^{\circledR}$ Dual A3 및 Filtek ${ }^{\mathrm{TM}}$ Z350 XT A1E로 코어를 축 조, 시편 별로 다른 코어를 사용하였다. 각 시편에 대해 온도를 낮추기 위한 압축공기를 불 때와 안 불 때로 나누어 디지 털 이미지를 촬영하였다. 치과의사 50 명과 치과대학 대학생 50 명 총 100 명에게 어떤 포스트가 코어와 가장 구별이 잘 되는 지를 설문조사 하였다.

결과: Luxacore $^{\circledR}$ Dual Blue에서는 Snowpost ${ }^{\circledR}$ 가, Luxacore ${ }^{\circledR}$ Dual A3에서는 Snowpost ${ }^{\circledR}$ 가, Filtek ${ }^{\mathrm{TM}}$ Z350 A1E에서는 MACRO-LOCK ${ }^{\mathrm{TM}}$ POST ILLUSION ${ }^{\mathrm{TM}} \mathrm{XRO}^{\circledR}$ 가 구별이 가장 잘되었다. 압축공기를 불어 온도를 내리면 나타나는 MACRO-LOCK ${ }^{\mathrm{TM}}$ POST ILLUSION ${ }^{\mathrm{TM}} \mathrm{XRO}^{\circledR}$ 의 색은 포스트와 코어의 구별을 더 용이하게 하였다.

결론: FRC-포스트와 복합레진 코어가 구별되는 정도는 색상차이에 따라 다름을 알 수 있었다.

(구강회복응용과학지 2015;31 (2) :75-85)

주요어: FRC-포스트; 코어; 색상차이; 구별; 포스트 제거; 온도에 따른 색상변화

*교신저자: 박세희

(210-702) 강원도 강릉시 죽헌길 7 강릉원주대학교 치과대학 치과보존학교실

Tel: 033-640-2760 | Fax: 033-640-3103 | E-mail: drendo@gwnu. ac. kr

접수일: 2015년 3월 13일 | 수정일: 2015년 5월 7일 | 채택일: 2015년 5월 31일 